\title{
Decolonialidade, Educação do Campo e Formação de professores de Matemática: por uma reforma agrária do saber
}

\author{
Filipe Santos Fernandes 1 \\ Universidade Federal de Minas Gerais (UFMG), Faculdade de Educação, Departamento de \\ Métodos e Técnicas de Ensino, Belo Horizonte, MG, Brasil
}

\author{
Eliziara Pereira Coutinho' \\ Camponesa e Coordenadora da Arca das Letras, Morro do Pilar, MG, Brasil
}

\section{Resumo}

Este artigo tem como objetivo apresentar relações entre a Decolonialidade, a Educação do Campo e a Formação de Professores. Assumindo uma opção decolonial, pensando novas possibilidades para a Universidade e tomando a Educação do Campo como um fenômeno de desobediência políticoepistêmica, pretende-se evidenciar como essas relações tensionam os modelos tradicionais de formação de professores de Matemática a partir de ações desenvolvidas no curso de Licenciatura em Educação do Campo, habilitação em Matemática, da Universidade Federal de Minas Gerais (UFMG). As discussões realizadas, que tomam a Etnomatemática como orientação, defendem processos formativos baseados em aspectos históricos, socioculturais e pedagógicos presentes em diferentes formas de vida, particularmente as camponesas, sendo a Universidade um possível espaço pluriepistêmico e fronteiriço que dialoga os saberes científico-acadêmicos com aqueles presentes nas práticas de culturas camponesas, afirmando positivamente suas diferenças para a superação das hegemonias e desigualdades campo-cidade no Brasil.

Palavras-chave: Colonialidade; Educação Matemática; Etnomatemática.

\section{Decoloniality, Rural Education and Mathematics Teacher Training: for a Agrarian Reform of Knowledge}

\begin{abstract}
This article aims to present the relations between Decoloniality, Rural Education and Teacher training. By assuming a decolonial perspective, conjecturing about new possibilities for the University and taking Rural Education as a phenomenon of political-epistemic disobedience, this article intends to show how these relations tension traditional models of mathematics teacher training
\end{abstract}

Submetido em: 26/06/2021 Aceito em: 18/08/2021 Publicado em: 03/09/2021

${ }^{1}$ Doutor em Educação Matemática pela Universidade Estadual Paulista "Júlio de Mesquita Filho" (UNESP/Rio Claro). Professor do Programa de Pós-Graduação em Educação: conhecimento e inclusão social, da Universidade Federal de Minas Gerias. Membro do grupo de estudos e pesquisas inSURgir. Endereço para correspondência: Av. Antônio Carlos, 6627, Pampulha, Belo Horizonte, Minas Gerais, CEP 31270-901. E-mail: fernandes.fjf@ gmail.com.

${ }^{2}$ Licenciada em Educação do Campo, com habilitação em Matemática, pela Universidade Federal de Minas Gerias (UFMG). Camponesa, bioconstrutora e coordenadora da Arca das Letras. Membro do Grupo de Estudos sobre Numeramento (GEN). E-mail: biraliza@gmail.com. 
based on actions developed in the Rural Education Degree course, mathematics qualification, from the Federal University of Minas Gerais (UFMG). The achieved discussions, which take Ethnomathematics as a guideline, defend teacher training processes based on historical, socio-cultural and pedagogical aspects present in different forms of life, particularly the peasants forms of life, while the University would occupy a possible multi-epistemic and borderline space that dialogues scientific-academic knowledge with those present in the practices of peasant cultures, positively affirming their differences in overcoming the hegemonies and the inequalities between rural areas and cities in Brazil.

Keywords: Coloniality; Mathematical Education; Ethnomathematics.

\section{Decolonialidad, Educación del Campo y Formación de Profesores de Matemática: por una Reforma (Agraria) del Saber}

\section{Resumen}

Este artículo tiene como objetivo presentar las relaciones entre la Decolonialidad, la Educación del Campo y la Formación de Profesores. Asumiendo una opción decolonial, pensando en nuevas posibilidades para la Universidad y tomando la Educación del Campo como un fenómeno de desobediencia político-epistémica, se pretende mostrar cómo estas relaciones tensan los modelos tradicionales de formación docente en Matemática a partir de las acciones desarrolladas en el curso de Licenciada en Educación del Campo, habilitación en Matemática, de la Universidad Federal de Minas Gerais (UFMG). Las discusiones llevadas a cabo, que toman como eje la Etnomatemática, defienden procesos de formación basados en aspectos históricos, socioculturales y pedagógicos presentes en diferentes formas de vida, particularmente campesinas, siendo la Universidad un posible espacio pluriepistémico y fronterizo en el que dialogan los saberes científico-académico con aquellos presente en las prácticas de las culturas campesinas, afirmando positivamente sus diferencias para la superación de las hegemonías y las desigualdades campo-ciudad en Brasil.

Palabras clave: Colonialidad; Educación Matemática; Etnomatemática.

\section{Introdução}

No dia 21 de novembro de 2005, a Universidade Federal de Minas Gerais (UFMG) realizava a aula inaugural do curso de Licenciatura em Educação do Campo (LECampo). Na ocasião, Armando Vieira, membro da direção nacional do Movimento dos Trabalhadores Rurais Sem Terra (MST) à época, afirmou que "As universidades ainda são o latifúndio, e nossa presença aqui [na UFMG] é uma ocupação". Reconhecendo esse lugar de privilégios, a ex-reitora da UFMG, professora Ana Lúcia Gazzola, destacou: "Deste lugar do privilégio é possível fazer uma reforma agrária do saber, ao estabelecer pontes e transformar a Universidade em um espaço onde os saberes populares e os saberes de todos os campos do conhecimento se enriqueçam e se estabeleçam mutuamente". ${ }^{3}$

As falas de Armando Vieira e Ana Lúcia Gazzola sintetizam as discussões apresentadas neste texto. Para tratar das relações entre a Decolonialidade, a Educação do Campo e a Formação de

${ }^{3}$ Disponível em: <https://www.ufmg.br/online/arquivos/002519.shtml>. Acesso em 20 jul. 2020. 
Professores, partimos da ideia da Universidade como espaço perpetuador de uma geopolítica do conhecimento de profundas relações com o padrão de poder mundial que, como destaca Quijano (2002), toma a ideia de raça como fundamento de classificação e dominação de poder, o capitalismo como meio de exploração social, o Estado como forma de controle e autoridade coletiva e o eurocentrismo como modo hegemônico de controle da subjetividade e da produção do conhecimento.

O texto encontra-se dividido em três partes. Na primeira, destacamos aspectos que evidenciam como a Educação do Campo, em especial os cursos de Licenciatura em Educação do Campo, atua em um movimento de decolonização do Ensino Superior brasileiro. Na segunda, assumindo a Etnomatemática como dimensão conceitual-epistêmica e prática, trazemos considerações sobre a formação de professores de Matemática no curso de Licenciatura em Educação do Campo da UFMG. $\mathrm{Na}$ terceira, mostramos como a disciplina Ensino das Funções permitiu a construção de conhecimentos matemáticos baseados em aspectos históricos, socioculturais e pedagógicos presentes em diferentes formas de vida, particularmente as camponesas.

\section{As Licenciaturas em Educação do Campo: decolonizar a Universidade brasileira}

Os cursos de Licenciatura em Educação do Campo surgiram como um projeto políticoeducacional que nasce de reivindicações de movimentos sociais ligados à luta pela terra, em resistência às estruturas fundiárias coloniais. As diretrizes que orientam a Educação do Campo, de um modo geral, e sua realização em cursos de Licenciatura em Educação do Campo, em particular, são "recentes e consideradas inovadoras, pois são concebidas no reconhecimento do dever do Estado em oferecer aos povos do campo uma educação adequada ao seu modo de viver, pensar e produzir" (AUAREK; VISEU, 2017, p. 1-2). Os cursos têm como objetivo promover uma formação de professores voltada às questões de grupos campesinos, buscando superar as hegemonias e dicotomias provocadas pelo padrão mundial de poder, incentivando moradores de áreas rurais a se tornarem professores e reivindicando o direito à educação nos locais onde residem.

A adoção da expressão Educação do Campo busca se opor à expressão Educação Rural. A primazia de um modo de vida urbano-industrial no Brasil subalternizou os diferentes modos de vida do campo e, no âmbito educacional, diferentes grupos que vivem em comunidades rurais - que comportam identidades como posseiros, boias-frias, ribeirinhos, vazanteiros, geraizeiros, atingidos por barragens, assentados, acampados, arrendatários, pequenos produtores e outros - foram subjugados na qualificação de suas comunidades, sujeitos e conhecimentos, tendo uma trajetória marginal no âmbito das políticas públicas de educação, o que inclui as orientações e ações de formação e qualificação de professores. A inserção desses grupos na agenda política, em especial, nas políticas educacionais é recente, e ainda não logrou desvencilhar-se, da visão depreciativa, no 
âmbito educacional, do termo "rural", como "condição de atraso", "tradicional" e "pré-científico", sendo comunidades, sujeitos e conhecimentos associados a um passado que pouco teria a contribuir com o projeto nacional de desenvolvimento.

A caracterização da Educação do Campo como um fenômeno de desobediência políticoepistêmica emerge da possibilidade que instaura de gerar desestabilizações no campo político, deslocando relações de poder por meio da afirmação dos povos do campo, historicamente subalternizados, e de sua contribuição para a enunciação e a emergência de epistemologias antes ausentes (FARIAS; FALEIRO, 2018). Especialmente por meio das Licenciaturas em Educação do Campo, o Movimento reforça um possível projeto de decolonização da Universidade, na medida em que rompe com dicotomias e hegemonias da Modernidade Ocidental, pautadas, especialmente, no controle capitalista, patriarcal e colonial das diferentes formas de vida que nela convivem.

A inserção dos cursos de Educação do Campo nas Universidades brasileiras provocou mudanças substanciais na concepção e na organização do Ensino Superior, particularmente na formação de professores. Destacaremos neste texto duas características desses cursos que atuam nessas mudanças: (1) a Pedagogia da Alternância e (2) a formação por áreas (e não por disciplinas) do conhecimento.

A Pedagogia da Alternância constitui um princípio e um sistema formativo que fortalece as formas de vida do campo, criando propostas curriculares que articulam espaços e tempos de formação na Universidade e nas comunidades rurais. No caso da UFMG, a Pedagogia da Alternância articulase em torno de dois espaço- tempos formativos: o Tempo Escola, momento em que os estudantes de diferentes comunidades rurais estão presencialmente na Universidade para um conjunto de atividades intensivas, e que ocorre, usualmente, nos meses de janeiro/fevereiro e junho/julho; e o Tempo Comunidade, momento em que os estudantes retornam para as localidades em que residem com questões com atividades e propostas de intervenção na comunidade, nas entidades rurais (associações, sindicatos, movimentos sociais, órgãos governamentais locais etc.) e/ou na escola.

No ano de 2018, a UFMG incluiu o ensino em alternância como possível formato pedagógico de referência para a construção de cursos e estruturas formativas, um movimento inovador no Ensino Superior brasileiro. A Resolução permite que qualquer curso da Universidade adote esse formato pedagógico, e não apenas o curso de Educação do Campo ou outros cursos ligados à formação de professores.

Art. $7^{\circ}$ Os cursos e estruturas formativas serão organizados tomando como referência um dos seguintes formatos pedagógicos: I - ensino presencial: [...]; II - ensino a distância: [...]; III - ensino em alternância: formato pedagógico no qual as atividades acadêmicas curriculares são desenvolvidas alternando períodos nos quais as turmas das atividades acadêmicas curriculares encontram-se reunidas em um só local e a carga horária é desenvolvida de forma concentrada e períodos nos quais as turmas 
das atividades acadêmicas curriculares encontram-se geograficamente dispersas junto a comunidades ou locais de trabalho externos à UFMG e a carga horária é disposta de forma a se compatibilizar com o regime de funcionamento próprio desses locais. $^{4}$

Entendemos que o formato pedagógico em alternância atua como um movimento de decolonização da Universidade, particularmente combatendo a perspectiva da Universidade como espaço privilegiado da produção de conhecimentos, "não apenas o lugar onde se produz o conhecimento que conduz ao progresso moral ou material da sociedade, mas também como núcleo vigilante dessa legitimidade" (CASTRO-GÓMEZ, 2007, p. 81)5. Ao alternar espaços e tempos, as Licenciaturas em Educação do Campo incluem as comunidades rurais (seus sujeitos, conhecimentos e entidades) na formação de professores, reconhecendo o papel fundamental que podem promover nesses processos formativos.

Além de adotarem a Pedagogia da Alternância, e procurando romper com a estrutura disciplinar do conhecimento no Ensino Superior, os cursos de Licenciatura em Educação do Campo articulam-se em torno da formação por áreas de conhecimento. Conforme Molina (2015, p. 153):

[...] a formação por áreas de conhecimento deve desenvolver-se tendo como intencionalidade maior promover estratégias que contribuam para superar a fragmentação do conhecimento, criando, propondo e promovendo ações docentes articuladas interdisciplinarmente, associadas intrinsecamente às transformações no funcionamento da escola e articuladas, ainda, às demandas da comunidade rural na qual se insere esta escola.

Podemos considerar que a proposta de formação por áreas de conhecimento visa, por um lado, esgarçar as fronteiras disciplinares que se acomodam a conhecimentos próprios do espaço científicoacadêmico, pautados no sistema-mundo capitalista, patriarcal e colonial, e, por outro, problematizar o espaço que essas disciplinas ocupam na educação escolar do campo (FERNANDES, 2019).

As áreas do conhecimento não são fixas e variam nas Universidades que ofertam esses cursos. No caso da UFMG, por exemplo, são ofertadas quatro áreas de conhecimento: (1) Línguas, Artes e Literatura; (2) Ciências da Vida e da Natureza; (3) Ciências Sociais e Humanidades e (4) Matemática. Ainda que isolada ${ }^{6}$, considerar a Matemática como uma área de conhecimento na formação de

\footnotetext{
${ }^{4}$ Documento Normas Gerais de Graduação da Universidade Federal de Minas Gerais (UFMG). Disponível em: <https://ufmg.br/comunicacao/publicacoes/boletim/edicao/novos-horizontes-para-a-graduacao/cepe-aprova-normasgerais-da-graduacao-e-resolucoes-correlatas>. Acesso em: 15 jan. 2020.

${ }^{5}$ No original: "no sólo el lugar donde se produce el conocimiento que conduce al progreso moral o material de la sociedad, sino como el núcleo vigilante de esa legitimidad".

${ }^{6}$ Não se explicitam as diferenças entre as áreas de conhecimento aqui, mas é necessário pontuar que elas existem motivadas por processos históricos, muitas vezes conflituosos, e por contingências durante a formação desses cursos nas Universidades e por compreensões epistemológicas distintas que permitem aproximações variadas entre campos disciplinares para a formação das áreas de conhecimento. Por exemplo, na UFMG, a Matemática é considerada uma área de conhecimento, ao passo que na Universidade Federal de Santa Catarina encontramos a área de conhecimento Ciências
} 
professores (e não como uma disciplina) supõe romper com dimensões universalizantes que delimitam seu contorno disciplinar, pensando-a não apenas na direção dos processos históricos e científicos Ocidentais que a constituem, mas como uma produção humana, socioculturalmente situada e que, quando diante das desigualdades e necessidades de grupos rurais, dissipa as características de infalibilidade, de rigor e de precisão, e de instrumento poderoso para a manutenção de padrões de poder estabelecidos.

Como discutimos mais à frente, esses rompimentos trazem aberturas tanto para o Ensino Superior quanto para as práticas pedagógicas em escolas rurais, envolvendo epistemologias ausentes, antes subalternizadas e silenciadas. Neste momento, interessa-nos considerar que a formação por áreas de conhecimento atua como um movimento de decolonização da Universidade na medida em que rompe com a estrutura arbórea e disciplinar do conhecimento, aquela que determina que "os conhecimentos têm hierarquias, especificidades, limites que marcam a diferença entre os certos campos do saber e outros, umas fronteiras epistêmicas que não podem ser transgredidas, cânones que definem seus procedimentos e funções particulares"7 (CASTRO-GÓMEZ, 2007, p. 81, tradução nossa).

Na dispersão ou subversão das fronteiras disciplinares, a formação por áreas do conhecimento desafia as hierarquias entre os conhecimentos que compõem os espaços científico-acadêmicos, buscando produzir uma Universidade de perspectivas pluriepistêmicas. Assim, diferentes sabedorias participam de forma qualificada dos processos formativos, sejam elas orientadas por padrões disciplinares ou situadas nas tradições das comunidades rurais que deles participam. A formação por áreas do conhecimento, aliada ao ensino em alternância, permite evidenciar nossas diferenças no espaço e no tempo, expondo as desigualdades que nos marcam, na intenção de superá-las. Procurase, então, substituir a hierarquização entre os conhecimentos por formas de gerar e gerir na Universidade diálogos que reconheçam a aproximação e a contaminação entre diferentes sabedorias como elementos indispensáveis à formação.

Considerando esses aspectos dos cursos de Licenciatura em Educação do Campo, discutimos, na próxima seção, como a Matemática e a formação de professores de Matemática são ressignificadas no curso ofertado pela UFMG, sendo, ambas, atravessadas pela Etnomatemática.

\footnotetext{
da Natureza e Matemática, na qual os conhecimentos e procedimentos reconhecíveis como matemáticos compartilham espaços e tempos curriculares com outros conhecimentos.

${ }^{7}$ No original: "los conocimientos tienen unas jerarquías, unas especialidades, unos límites que marcan la diferencia entre unos campos del saber y otros, unas fronteras epistémicas que no pueden ser transgredidas, unos cánones que definen sus procedimientos y sus funciones particulares".
} 


\section{Formação de Professores de Matemática em Licenciaturas em Educação do Campo: atravessamentos pela Etnomatemática}

No Brasil, a formação de professores de Matemática é marcada pelo papel periférico dos conhecimentos pedagógicos e pelo distanciamento das questões relativas à educação escolar (GOMES, 2016). Nesse cenário, destaca-se na formação de professores de Matemática a prevalência de conteúdos matemáticos em um nítido direcionamento profissional e científico, sendo pouco discutidos em suas contribuições na formação docente e inexpressivamente relacionados à diversidade sociocultural que compõe a educação brasileira.

Essa postura, ainda que possa favorecer o desenvolvimento da pesquisa em Matemática, tem severas implicações se a avaliarmos considerando seus desdobramentos socioculturais e educacionais. Primeiro, porque tal proposta dá centralidade à preparação de sujeitos para a vida em uma sociedade marcada pelo desejo de progresso, creditado a um desenvolvimento científico e tecnológico que, muitas vezes, promove e intensifica as desigualdades sociais e educacionais campocidade. Segundo, porque essa proposta reforça práticas formativas de professores de Matemática -e, em decorrência, práticas escolares - que prescrevem e promovem: a individualização do pensamento; a especificação e a hierarquização de saberes; a naturalização da seriação, da mecanização e da memorização nos processos de ensino-aprendizagem; e a adaptação da lógica de produção, de avaliação e de gratificação da vida capitalista ao espaço escolar.

Diferenciando-se dessa proposta, a perspectiva da formação por área de conhecimento, intensificada com a criação e a expansão das Licenciaturas em Educação do Campo (MOLINA, 2015), promove deslocamentos e rompimentos políticos, epistemológicos e estratégicos. Dos pontos de vista político e epistemológico, a proposta tem como intenção repensar os modos de produção, de organização e de circulação de saberes e fazeres na Universidade e na escola, problematizando as fronteiras entre as disciplinas que marcam a formação de professores. Do ponto de vista estratégico, a proposta busca ampliar as possibilidades de oferta de uma Educação Básica no campo articulada às demandas das comunidades campesinas. Podemos dizer, então, que a aproximação da perspectiva da área de conhecimento nos cenários de formação de professores de Matemática permite interpelar as lógicas urbanocêntricas que permeiam a educação escolar e que marcam as desigualdades educacionais campo-cidade.

É nesse sentido de desconstrução que surge a potência do pensamento Etnomatemático na Educação do Campo e nos processos de formação de professores a ela relacionados. Acreditamos que a Etnomatemática permite esgarçar, multiplicar, confrontar e romper com compreensões sobre o conhecimento matemático, indicando caminhos outros para os processos formativos de professores de matemática. Nas palavras de D’Ambrosio (2002, p. 17): 
[...] a Matemática, com seu caráter de infalibilidade, de rigor, de precisão e de ser um instrumento essencial e poderoso no mundo moderno, teve sua presença firmada excluindo outras formas de pensamento. Na verdade, ser racional é identificado com dominar a Matemática. A Matemática se apresenta como um deus mais sábio, mais milagroso e mais poderoso que as divindades tradicionais e outras tradições culturais.

Uma importante contribuição da Etnomatemática nesse cenário é a possibilidade de afirmação dos diferentes sujeitos e seus modos de vida. No âmbito específico da Educação do Campo, deve-se assumir que a sustentabilidade das comunidades rurais é um dos principais objetivos dessa formação, sendo sua finalidade a valorização e a mobilização dos diferentes modos de saber, de fazer e de ser dos sujeitos campesinos nos processos educacionais que envolvem a matemática. Em outras palavras, há uma necessidade de redirecionamento da Matemática para a constituição de um projeto de campo específico, com destaque para processos educacionais que valorizem suas especificidades. Esse redirecionamento, contudo, é difícil de se perceber e de se realizar, especialmente pelo inevitável tensionamento que provocam em dimensões epistemológicas que conferem à matemática uma posição homogeneizadora das práticas escolares no mundo moderno. A esse respeito, Howley et al. (2010, p. 3) apontam que:

A ironia é que a Matemática é, talvez, a disciplina intelectual mais amplamente reconhecida por ter permitido o trabalho da ciência, da tecnologia e da engenharia modernas, do século XVII até o presente. Do ponto de vista dos críticos, pelo menos, os educadores podem precisar perguntar de que lado está sua versão da Matemática: exploração voraz ou propósito comum. ${ }^{8}$

Tratar com seriedade tal ironia - que contrapõe o caráter homogeneizador da dimensão disciplinar da matemática à valorização e à mobilização dos diferentes modos de saber, de fazer e de ser de sujeitos, inclusive campesinos, nos processos educacionais que envolvem a Matemática -, exige certos cuidados, lançando uma série de desafios, levantados em Fernandes (2019, p. 31-32):

[...] o que significa, no âmbito epistemológico e formativo, pensar a matemática como uma área de conhecimento, contrapondo-a ao modelo disciplinar? Como pensar espaços formativos e desenhos curriculares nos quais a disciplina matemática, usualmente fundamentada na fragmentação do conhecimento e estabelecida como metanarrativa da modernidade, dê lugar a discussões que envolvam a matemática como área de conhecimento, meio de transformação da educação articulado às demandas do campo? Como estabelecer estratégias de ensino que esgarcem as fronteiras disciplinares e tomem a formação de professores de matemática a serviço da vida e da superação das marcas de desigualdade e injustiça ainda presentes no campo brasileiro?

\footnotetext{
${ }^{8}$ No original: "The irony is that mathematics is perhaps the intellectual discipline most widely acknowledged to have enabled the work of modernist science, technology, and engineering from the seventeenth century to the present. From the vantage of the critics, at least, educators may need to ask which side their version of mathematics is on: rapacious exploitation or common purpose".
} 
No Brasil, diferentes ações têm permitido tratar tais questões. Uma delas é a própria criação e a expansão de cursos de Licenciatura em Educação do Campo que, ao assumirem uma formação por áreas de conhecimento e ao adotarem a alternância de tempos e espaços de formação, têm aliado dimensões socioculturais da Matemática à formação de professores. Nesses cursos, ainda que também se reconheça a presença de aspectos disciplinares da Matemática, é possível identificar que os contextos socioculturais camponeses compõem boa parte dos projetos curriculares, explicitando a importância de articular a formação do professor e da professora de Matemática aos saberes e fazeres próprios do modo de vida camponês (SACHS; ELIAS, 2016).

No curso de Licenciatura em Educação do Campo da UFMG, diferentes disciplinas específicas da habilitação em Matemática têm mobilizado a Etnomatemática como proposta formativa em, pelo menos, duas dimensões. Em uma dimensão conceitual-epistêmica, o pensamento etnomatemático surge como possibilidade de evidenciar as diferenças no espaço e no instante e de enfrentar contemporaneamente as crises da verdade, do conhecimento e da racionalidade (CLARETO, 2009). Em uma dimensão prática, temos a ruptura com os modos de produção, organização e divulgação da Matemática baseados estritamente no conhecimento produzido pela comunidade dos matemáticos. As diferentes matemáticas da formação dos professores se baseiam na relação ou criação de um conhecimento matemático escolar imerso em aspectos históricos, socioculturais e pedagógicos.

\section{Movimentos da disciplina Estudo das Funções}

A título de exemplo, tomamos a disciplina Estudo das Funções, ministrada no primeiro semestre de 2018 para os estudantes da habilitação em Matemática. Em geral, o tema função reivindica no espaço escolar abordagens do ponto de vista da Teoria de Conjuntos, abarcando, quase que estritamente, a relação entre conjuntos numéricos, suas características, tipologias, representações gráficas e aplicações. Contudo, tendo como orientação o pensamento etnomatemático, propomos na disciplina dar centralidade a discussões sobre um mundo em relação e transformação e sobre a possibilidade de criação de um instrumental matemático para sua compreensão e expressão. Optamos por pensar como as ideias relacionadas ao conceito de função estão associadas à previsibilidade e ao controle e como pode ser socioculturalmente construído e manifestado.

No período do Tempo Escola, com os estudantes presencialmente na UFMG, focamos ideias e procedimentos que envolvem o conceito de função, bem como o modo como esse conceito se desenvolve como conhecimento escolar. Nesse momento, não nos desviamos das relações com a Teoria de Conjuntos, visto que práticas pedagógicas desenvolvidas na escola estão, quase exclusivamente, tratadas segundo essa perspectiva. 
Para o Tempo Comunidade, momento em que os estudantes retornam aos seus locais de moradia com atividades decorrentes de uma ou de um conjunto de disciplinas, propusemos aos estudantes um olhar para transformações e relações presentes em práticas socioculturais de suas comunidades, mesmo que nessas transformações e relações não fosse possível reconhecer aspectos do conceito de função trabalhado na escola, particularmente o estabelecimento de uma correspondência numérica entre grandezas. A proposta dessa atividade é reproduzida a seguir:

No primeiro semestre do curso, fizemos uma atividade envolvendo cartas, na qual vocês descreveram diferentes práticas matemáticas presentes em suas comunidades. Para "refrescar" nossas memórias, trago abaixo dois trechos de cartas, da Angélica e do Israel:

"Depois dos primeiros dias de curso, percebi que em minha cidade existem muitas matemáticas, e algumas me chamam a atenção. São elas: a medição da goma, que é medida por "prato"; o "metro" da areia, que são seis carrinhos de mão; e a "carga" de rapadura, que são trinta rapaduras." (Israel)

"Como a maioria das famílias que vivem aqui tem a sua renda baseada no cultivo de mandioca, então encontramos matemática do plantio até o momento da secagem do polvilho, que chamamos de goma. É curioso que até na hora que as donas de casa vão medir a goma para fazerem suas receitas que utilizam o produto, elas têm seus métodos. Por exemplo, três litros de goma elas chamam de prato. Se alguém de outro lugar ouvisse falar, certamente iria pensar que seria apenas um prato usado como utensílio doméstico, mas aqui todos conhecem como três litros de goma." (Angélica)

Como podemos perceber, muitas dessas práticas envolvem grandezas ou relações entre grandezas. No caso de Israel, temos, por exemplo, a relação entre a quantidade de rapaduras e o número de "cargas"; no caso de Angélica, entre a quantidade de goma, o número de litros e o número de "pratos", indicando até uma possível confusão entre a linguagem tradicional (o prato como utensílio) e a linguagem usada na comunidade (o prato como unidade de medida).

A proposta de atividade é, então, que você busque por práticas em sua comunidade que envolvam relações entre grandezas. Converse com um morador que lida com essa relação em seu trabalho ou lazer e realize as discussões abaixo. Sempre que possível, apresente fotografias, desenhos e/ou trechos de conversas para incrementar sua discussão.

a) Em qual atividade você observa essa relação? Como ela está presente em sua comunidade? (Por exemplo, a "carga" está presente na atividade de comercialização das rapaduras)

b) Apresente o morador com o qual conversou. Ele realiza essa atividade como forma de trabalho ou lazer? Com que frequência a realiza?

c) Quais são as grandezas envolvidas? Há uma relação numérica entre elas? (Por exemplo, "três litros de goma é o mesmo que um prato")

d) Pergunte ao morador sobre a história dessa atividade em sua comunidade. Desde quando ela está presente? Com quem aprendeu? Essa atividade tem se mantido ou se perdido com o passar do tempo? Por quê?

e) Para essa atividade, há algum instrumento de medida ou material específico? Se sim, fotografe-o e explique o seu funcionamento.

f) Como essa atividade poderia ser explorada em uma aula de matemática? Faça uma breve discussão. 
eISSN: $2526-9062$

O interesse em trazer essa proposta na íntegra é evidenciar uma possibilidade do formato pedagógico em alternância, retomando ações que se desenvolveram em momentos anteriores do curso e utilizando-as para a configuração de novas propostas. Como se pode perceber, os estudantes deveriam discutir as transformações e relações observadas a partir de suas comunidades em uma perspectiva pedagógica.

A estudante Eliziara ${ }^{9}$, também autora deste texto, investigou a produção do chapéu de palha do coqueiro Indaiá, na Comunidade Lapinha, município de Morro do Pilar, Minas Gerais ${ }^{10}$. A seguir, trazemos algumas imagens registradas pela estudante e falas que nos ajudam a pensar a participação do pensamento etnomatemático nas ações formativas do curso.

Fotografias 1 a 5. Fotos da produção do chapéu de palha (Morro do Pilar, MG).
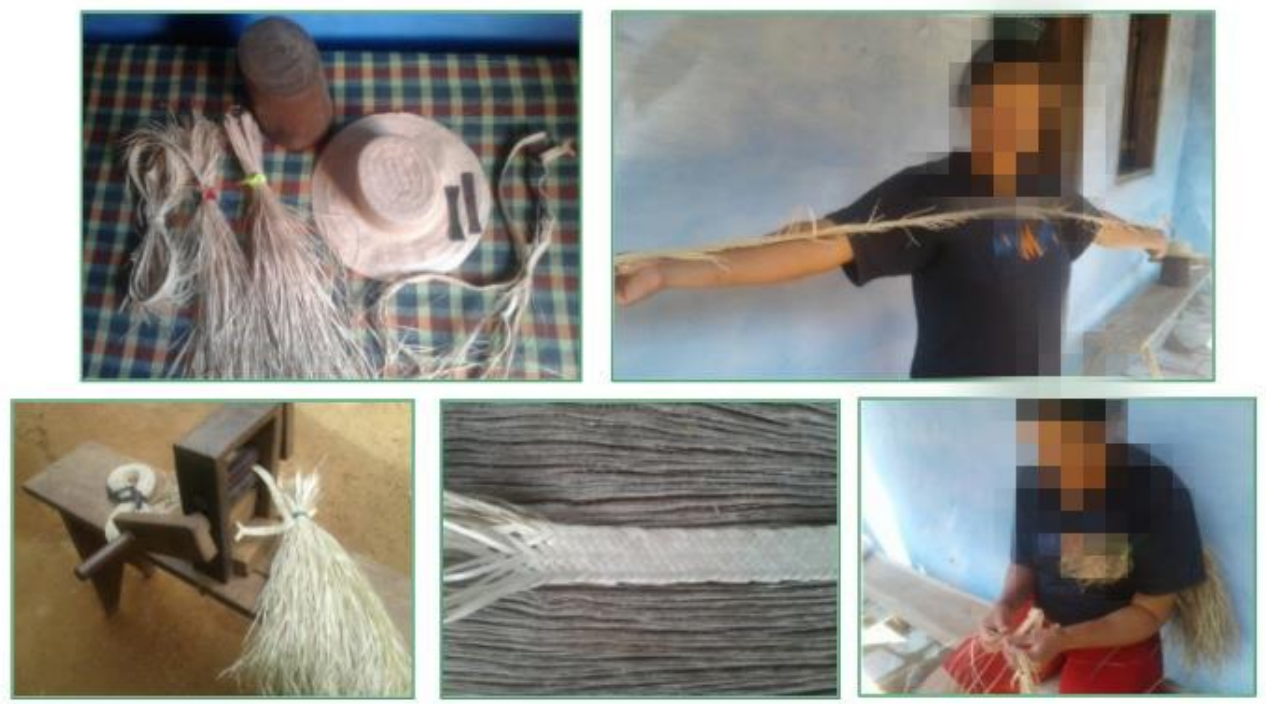

Fonte: Arquivo pessoal de Eliziara.

$\mathrm{Na}$ investigação de Eliziara podemos destacar três aspectos. O primeiro, histórico, é evidenciado em sua conversa com Dona Maria ${ }^{11}$, 70 anos, trançadeira de sua comunidade. Há nessa conversa um sentido de reconstrução da memória da comunidade a partir da prática e dos conceitos matemáticos observados. Nessa direção, Eliziara escreve em seu trabalho:

O feitio do chapéu de palha de Coqueiro Indaiá na região de Morro do Pilar representa uma tradição secular. Praticada pelas mulheres trançadeiras, essa

\footnotetext{
${ }^{9}$ Os estudantes mencionados neste texto autorizaram a divulgação de seus nomes reais.

${ }^{10} \mathrm{O}$ trabalho de Eliziara com o chapéu de palha do coqueiro Indaiá não se limitou a essa atividade. Em 2020, Eliziara defendeu o Trabalho de Conclusão de Curso intitulado "Não precisa ser coisa com coisa, porque não é coisa com coisa não!' Práticas de numeramento na produção do chapéu de palha de coqueiro Indaiá na comunidade Lapinha em Morro do Pilar - MG, que busca descrever o processo de confecção do chapéu de palha pelas trançadeiras da Comunidade Lapinha e reconhecer nesse processo como essas mulheres protagonizam práticas de numeramento.

${ }^{11}$ Utilizamos, aqui, um nome fictício.
} 
sabedoria vem sendo mantida de geração a geração. Pode-se observar diversas e diferentes formas de matemática nessa prática, desde conhecer a quantidade de palha para se fazer uma trança até o comprimento da trança para se costurar determinado tipo de chapéu.

Um segundo aspecto, sociocultural, está ligado à presença de uma prática artística e econômica em sua comunidade. No caso, destacam-se questões do cotidiano, geracionais e de gênero que circunstanciam a produção do chapéu de palha. Como destaca a estudante:

Conversando com a moradora trançadeira, Maria, de 70 anos, pude ouvir histórias sobre a vida dura do passado e do quanto a renda da produção de chapéu foi importante para manter as necessidades básicas da sua família no passado. Maria conta que se trançava à noite com a luz da chama de lascas da Candeia, madeira de boa combustão, que era queimada para iluminar o trabalho de trançar e costurar chapéus.

Além disso, podemos destacar um aspecto pedagógico nesse trabalho: a elaboração de possíveis encontros dessa prática com o espaço escolar, incitando relações com conhecimentos escolares já existentes ou a criação de novos conhecimentos. Na avaliação de Eliziara:

Para levar essa atividade campesina para uma aula de matemática poderíamos, por exemplo, medir a braça de cada aluno e verificar que cada um tem uma medida. Verificar a medida em metros e se essa medida é a mesma da altura da pessoa, pois as trançadeiras afirmam ser. Poderíamos visitar uma família produtora e apresentar os vários instrumentos utilizados nesse trabalho, como o ferro de rachar as palhas, o escassador para achatar a trança, a fôrma de madeira para dar forma ao chapéu. Poderíamos pedir para que os alunos que têm trançadeiras na família peçam emprestado os instrumentos para exposição na escola durante uma feira de cultura ou, ainda, que fosse apresentada a forma de medir que é utilizada nesse trabalho. Enfim, valorizar essa sabedoria local ancestral.

Ainda que exista no trabalho de Eliziara um reconhecimento da importância dos conceitos matemáticos escolares usuais, percebe-se que esses se colocam a serviço das perspectivas educacionais da Educação do Campo, afirmando sujeitos, comunidades e coletivos que a compõem. No trecho a seguir, ao tratar das unidades utilizadas na medição das tranças, a estudante expõe um distanciamento em relação às práticas de medida adotadas na Modernidade, (porque) apoiadas na padronização, na universalidade e na impessoalidade.

O comprimento da trança é medido em braça, que é uma forma de medir feita com os braços abertos segurando a trança na ponta dos dedos. Para um chapéu dependendo do tamanho da pessoa é necessário de 5 a 7 braças. Assim cada pessoa vai descobrindo quantas braças ela precisa trançar para costurar um chapéu. A medida convencional, o metro, não é sequer mencionada nessa prática. Há uma independência nesse sistema de medidas. 
Particularmente, a referência a uma "independência" sugere uma não subordinação dessa prática a processos usuais de medição, em procedimentos, unidades ou tecnologias "oficiais". Tratase, entendemos, da indicação de uma luta pela existência e pela resistência de saberes, em uma dupla desobediência: política, pois irrompe regras estabelecidas, em um processo que resiste a um modo idealizado de medir, afirmando outras existências de um processo; e epistêmica, pois lança mão de saberes de grupos socioculturais para confrontar processos de dependência de uma Matemática “oficial”, impedindo que saberes idealizados subalternizem aqueles que as artesãs praticam.

Acreditamos que a descrição de Eliziara ajuda a pensar o exercício da colonialidade que se dá pela Matemática, chamando a nossa atenção para a existência de saberes que, sendo ou não classificados como "matemáticos" por esses grupos socioculturais, enfrentam, subvertem, resistem e insurgem a processos colonizatórios, impedindo, ainda que localmente, que certas existências sejam subalternizadas, invisibilizadas, desumanizadas ou, em processos extremamente violentos, exterminadas.

Com isso, podemos recolocar um papel político da Etnomatemática, a ser amplamente discutido em nossa comunidade: entender como, apesar da colonialidade, diferentes modos de saber, fazer e de ser desobedecem ao padrão de poder mundial buscando afirmar as (re)existências de grupos socioculturais.

\section{Considerações finais}

Neste texto, buscamos mostrar como a Educação do Campo, em atravessamentos decoloniais, promove deslocamentos e rupturas no Ensino Superior e na formação de professores. Particularmente, as atividades desenvolvidas na formação de professores de Matemática no curso de Licenciatura em Educação do Campo da UFMG evidenciam tensionamentos dos modelos hegemônicos de formação, em seus espaços, tempos e conhecimentos, incitando a produção de saberes matemáticos escolares baseados em aspectos históricos, socioculturais e pedagógicos presentes em diferentes formas de vida.

Com isso, propomos uma Universidade como espaço fronteiriço que põe em diálogo os saberes científico-acadêmicos com os saberes presentes nas práticas de suas culturas, afirmando positivamente suas diferenças. Esperamos com essa discussão promover movimentos de desobediência político-epistêmica em relação ao projeto Modernidade/Colonialidade, sendo a formação docente um especial cenário para a construção desse projeto.

Por fim, acreditamos que as discussões aqui empreendidas se desdobram em reflexões sobre novos papeis políticos da Etnomatemática na formação de professores e professoras de Matemática. Aliados à decolonialidade e à Educação do Campo, esses papeis podem impedir que certas 
existências, tanto de saberes quanto de sujeitos, sejam suprimidas, afirmando os modos de vida de grupos socioculturais camponeses.

\section{Agradecimentos}

Agradecemos, profunda e afetuosamente, a professora Maria da Conceição Ferreira Reis Fonseca, nossa Ção, pela leitura e pelas contribuições a este texto.

\section{Referências}

AUAREK, W. A.; VISEU, F. Especificidades da formação do professor de matemática para escolas do campo. Revista de estudios y investigación en psicología y educación, v. extr., n. 6, p. 1-6, 2017.

CASTRO-GÓMEZ, S. Decolonizar la universidad. La hybris del punto cero y el diálogo de saberes. In: CASTRO-GÓMEZ, S.; GROSFOGEL, R. (Eds.). El giro decolonial: reflexiones para una diversidad epistémica más allá del capitalismo global. Bogotá: Siglo del Hombre Editores; Universidad Central, Instituto de Estudios Sociales Contemporáneos e Pontificia Universidad Javeriana, Instituto Pensar, 2007. p. 79-92.

CLARETO, S. M. Conhecimento, inventividade e experiência: potências do pensamento etnomatemático. In: FANTINATO, M. C. C. B. (Ed.). Etnomatemática - novos caminhos teóricos e metodológicos. Niterói, Brasil: Universidade Federal Fluminense, 2009. p. 125-134.

COUTINHO, E. P. "Não precisa ser coisa com coisa, porque não é coisa com coisa não!" Práticas de numeramento na produção do chapéu de palha de coqueiro Indaiá na comunidade Lapinha em Morro do Pilar - MG. 2020. 73 p. Monografia (Licenciatura em Educação do Campo). Faculdade de Educação, Universidade Federal de Minas Gerais, Belo Horizonte, 2020.

D’AMBROSIO, U. Etnomatemática e educação. Educação e Reflexão, v. 10, n. 1, p. 7-20, 2002.

FARIAS, M. N.; FALEIRO, W. Movimento de educação do campo enquanto fenômeno decolonial: afirmando percursos de desobediência político-epistemológica. Revista Educação e Cultura Contemporânea, v. 15, n. 39, p. 357-374, 2018.

FERNANDES, F. S. Formação de Professores de Matemática em Licenciaturas em Educação do Campo: entre cartas, epistemologias e currículos. BOLEMA, v. 33, n. 63, p. 27-44, abr. 2019. Disponível em: <https://www.scielo.br/pdf/bolema/v33n63/1980-4415-bolema-33-63-0027.pdf>. Acesso em: 15 de jul. de 2020.

GIRALDO, V.; FERNANDES, F. S. Caravelas à vista: giros decoloniais e caminhos de resistência na formação de professoras e professores que ensinam Matemática. Perspectivas da Educação Matemática, v. 12, n. 30, p. 467-501, 2020. Disponível em: $<$ https://periodicos.ufms.br/index.php/pedmat/article/view/9620/7175>. Acesso em: 2 de set. de 2020.

GOMES, M. L. M. Os 80 anos do primeiro curso de Matemática brasileiro: sentidos possíveis de uma comemoração acerca da formação de professores no Brasil. BOLEMA, v. 30, n. 55, p. 424- 
438, ago. 2016. Disponível em: <https://www.scielo.br/pdf/bolema/v30n55/1980-4415-bolema-3055-0424.pdf>. Acesso em: 18 de fev. de 2020.

HOWLEY, A. et al. Community and place in mathematics instruction in selected rural schools. Athens, USA: ACCLAIM, 2010. Disponível em: 〈https://files.eric.ed.gov/fulltext/ED512400.pdf〉. Acesso em: 3 de set. de 2020.

MOLINA, M. C. Expansão das licenciaturas em Educação do Campo: desafios e potencialidade. Educar em Revista, v. 55, n. 1, p. 145-166, jan./mar. 2015. Disponível em: <https://www.scielo.br/pdf/er/n55/0101-4358-er-55-00145.pdf >. Acesso em: 15 de ago. de 2020.

QUIJANO, A. Colonialidade, poder, globalização e democracia. Novos Rumos, v. 17, n. 37, p. 428, 2002. Disponível em:

$<$ http://revistas.marilia.unesp.br/index.php/novosrumos/article/view/2192>. Acesso em: 3 de set. de 2020.

SACHS, L.; ELIAS, H. R. A formação matemática nos cursos de licenciatura em Educação do Campo. BOLEMA, v. 30, n. 55, p. 439-454, maio/ago. 2016. Disponível em: <https://www.scielo.br/pdf/bolema/v30n55/1980-4415-bolema-30-55-0439.pdf >. Acesso em 15 de jul. de 2020. 